Military Technical College Kobry El-Kobbah, Cairo, Egypt.

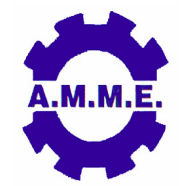

\title{
MONITORING NATURAL PIT PROGRESSION ON A SLOW SPEED THRUST BEARING WITH ACOUSTIC EMISSION
}

\author{
M. Elforjani* and D. Mba**
}

\begin{abstract}
This paper presents results of the use of $A E$ signatures to detect the on-set and propagation of cracks associated with a thrust bearing race. To facilitate the investigation a special purpose built test-rig was employed which allowed for accelerated crack initiation on a bearing race. It is concluded that sub-surface initiation and crack propagation is detectable with $A E$ technology. The results revealed that selecting the $\mathrm{AE}$ technique can significantly improve defect identification in comparison to conventional methods of analysis.
\end{abstract}

\section{KEY WORDS}

Acoustic Emission, condition monitoring, cracks, thrust bearings.

Assistant Prof., School of Engineering, Cranfield University, Cranfield, Bedfordshire, MK43 OAL, UK. Email: elforjani@gmail.com.

** Professor, School of Engineering, Cranfield University, Cranfield, Bedfordshire, MK43 OAL, UK. Email: D.Mba@Cranfield.ac.uk. 


\section{INTRODUCTION}

Acoustic Emission $(\mathrm{AE})$ is defined as the range of phenomena that results in the generation of propagation waves due to the rapid release of energy from localised sources within a material [1]; typical frequency content of $\mathrm{AE}$ is between $100 \mathrm{kHz}$ to $1 \mathrm{MHz}$. A recent review has detailed the application of $A E$ technology to monitoring a range of rotating machines [2]. Sources of $A E$ in rotating machinery include impacting, cyclic fatigue, friction, turbulence, etc. For instance, the interaction of surface asperities and impingement of the bearing rollers over a defect on an outer race will result in the generation of acoustic emission. These emissions propagate on the surface of the material as Rayleigh waves and are measured with an AE sensor. Other wave types associated with the propagation of AE include Lamb, Longitudinal and Shear waves. Jamaludin et al [3] presented the challenges faced with using the vibration technology to monitor the mechanical integrity of slow speed bearings (less than 60rpm) and suggested that the AE technology could overcome such difficulties.

To date most published work on the application of the $\mathrm{AE}$ to monitoring bearing mechanical integrity have been conducted on artificially or 'seeded' damage which are generally induced with an electrical discharge system, engraving machine or by introducing debris into the lubricant. The main constraint with the application of the $A E$ technology is attenuation [4]. The only investigation on identification of the onset of natural degradation in bearings with $\mathrm{AE}$ was presented by Yoshioka [5]. This focused on detection of a rolling contact subsurface fatigue crack using $\mathrm{AE}$ technology. An acoustic emission source locating system was developed. Yoshioka presented results where cracks were actually found parallel to the surface. It is worth noting that Yoshioka employed a bearing with only three rolling elements which is not representative of a typical operational bearing. Moreover, Yoshioka terminated $A E$ tests once $A E$ activity increased as such the propagation of identified sub-surface defects to surface defects were not monitored. This work builds further on the work of Yoshioka by monitoring not only the initiation of cracks, but also its propagation to spalls or surface defects on a conventional bearing. The location of the AE source was also monitored throughout the test sequence in order to validate that the AE's generated throughout the test period can be eventually attributed to the surface defect noted at the end of the test.

\section{EXPERIMENTAL PROCEDURE AND EQUIPMENT}

Bearing run to failure tests were performed under natural damage conditions on this specially designed test rig. To accelerate crack initiation, a combination of a thrust ball bearing and a thrust roller bearing was selected. One race of ball bearing (SKF 51210) was replaced with a flat race taken from the roller bearing (SKF 81210 TN) of the same size, see Fig. 1. Consequently, the rolling ball elements on a flat track caused very high contact pressure in excess of $6,000 \mathrm{MPa}$. To determine the subsurface stresses on the test bearing and thereby estimate the time to surface fatigue on the race the following theories were employed: the Hertizan theory for determining surface stresses and deformations, Thomas and Hoersh theory for subsurface stress, and, the Lundberg and Palmgren theory for fatigue evaluation. For the grooved race the standard procedure, as described by BS (British Standards 
Documents) 5512; 1991, was employed for determining dynamic load rating. The test rig rotational speed was $72 \mathrm{rpm}$ and an axial load of $50 \mathrm{kN}$ was employed for this particular test. The test rig layout can be seen in Fig. 2 .

A schematic of the data acquisition process is detailed in Fig. 3. The AE acquisition system employed commercially available piezoelectric sensors (Physical Acoustic Corporation type "PICO") with an operating range of $200-750 \mathrm{kHz}$ at temperature ranging from -65 to $177^{\circ} \mathrm{C}$. Four acoustic sensors, together with two thermocouples (RoHS-Type: $\mathrm{J} \times 1 \mathrm{M}$ 455-4371) were attached to the back of the flat raceway using superglue. The acoustic sensors were connected a data acquisition system through a preamplifier, set at $40 \mathrm{~dB}$ gain. The system was continuously set to acquire $\mathrm{AE}$ waveforms at $2 \mathrm{MHz}$ sampling rate whilst $A E$ parameters such as counts, r.m.s, average signal level (ASL), maximum amplitude and absolute energy (recorded over a time constant of $10 \mathrm{~ms}$ and sampling rate of $100 \mathrm{~Hz}$ ).

\section{EXPERIMENTAL RESULTS, OBSERVATIONS AND DISCUSSIONS}

Under normal conditions of load, rotational speed and good alignment, surface damage begins with small cracks, located between the surface of the flat track and the rolling elements, which gradually propagate to the surface generating detectable $A E$ signals. During the first hour of the test, an increase in $A E$ activity levels and temperature was noted. This was attributed to run-in as after this period (1-hr) all measured $\mathrm{AE}$ parameters and temperature remained constant for another 7-hrs. Figure 4 shows monitoring of the $A E$ levels over 16-hours of bearing operation that reflect the general observations associated with over a dozen experimental tests. It was observed that at approximately 9.5-hrs into the test AE showed significant increases in AE activity until the test was terminated (16-hrs). Bearing temperature was measured by two thermocouples channels attached to the back of the flat raceway. Following run-in (0- to $1-\mathrm{hr}$ ) the bearing temperature stabilized at $36{ }^{\circ} \mathrm{C}$. After 16-hrs operation a maximum temperature of $38^{\circ} \mathrm{C}$ was recorded. Figures 4 and 5 show trends of traditional $A E$ parameters. All of which show significant increase in $A E$ activity from 9-hrs of operation. It is also worth noting a small increase in AE levels (Counts and Amplitude) at 4-hrs of operation. AE waveforms, recorded during the test, clearly showed $\mathrm{AE}$ transient events after 4-hours, see Fig. 6 . The waveform at 10-hrs operations shows a periodicity of $A E$ transient bursts at approximately $(18 \mathrm{~Hz})$ whilst a strong evidence of $9 \mathrm{~Hz}$ on the termination of the test (16-hrs), see Figs. 6 and 7; the relevance of this will be evident later in the paper.

The capability of $\mathrm{AE}$ to determine source locations of signals emanating in real time from materials under load is one of the significant advantages $A E$ offers over other non-destructive test (NDT) technologies. In acoustic emission applications, AE signals travelling through the medium are attenuated and arrive at different sensors with certain time delay. This delay can be attributed to the distance between the source (defect) and AE sensors, and, with knowledge of the signal velocity the location of the AE source can be identified. For this particular investigation efforts were made to identify the defect location (AE source location) in real-time. This was accomplished by identifying the wave velocity on the ring experimentally. Source location estimations employed in the bearing test provided another simple and rapid means to identify and locate the crack initiation and propagation to surface spall. The 
source location over the duration of this test is presented in Figs. 8 to 11; the regions where the surface damage occurred are highlighted by the 'box' section. The location plots show cumulative energy over the test simulation. It is worth noting that only $\mathrm{AE}$ events above a threshold of $52 \mathrm{~dB}$ contribute to the source location. Whenever the threshold is exceeded, the location of the source is computed and identified. Evident from these figures was that the start of the test (run-in), an $A E$ activity was distributed across a very broad circumferential position on the bearing ring. This is not surprising as the run-in period is associated with considerable $A E$ events whilst the bearing dynamics stabilize, see fig. 8. After 4- to 10-hrs geometric concentrations of $\mathrm{AE}$ activity in the eventual defect zones became evident with values of $5 \times 104$ atto-Joules (zone1), 7 × 105 atto-Joules (zone 2) and $5 \times 104$ attoJoules (zone 3), noted at 10-hrs operation, see figs. 9 and 10 . On the termination of the test (16-hrs), the concentration of the $A E$ sources was clearly located in the highlighted damage region, see Fig. 11; maximum energy values of $5 \times 107$ attoJoules (zone1), 52 × 107 atto-Joules (zone 2) and $89 \times 107$ atto-Joules (zone 3) were noted.

\section{CONCLUSION}

The study has demonstrated that AE parameters such as energy, count, amplitude and ASL are reliable, robust and sensitive to the detection of incipient cracks and surface spalls in slow speed bearing. It can be concluded that sub-surface initiation and crack propagation is detectable with AE technology. This study also successfully showed the ability to determine the source of AE during operation.

\section{REFERENCES}

[1] ISO (International Standards Organisation Documents) 22096; Condition monitoring and diagnosis of machines - Acoustic Emission. 2007.

[2] Mba, D., Rao, Raj B. K. N. Development of Acoustic Emission Technology for Condition Monitoring and Diagnosis of Rotating Machines: Bearings, Pumps, Gearboxes, Engines, and Rotating Structures. The Shock and Vibration Digest 2006 38: 3-16.

[3] Jamaludin N.; Mba D.; Bannister R. H., Condition Monitoring of Slow-Speed Rolling Element Bearings Using Stress Waves, Proceedings of the IMECHE Part E Journal of Process Mechanical Engineering, Volume 215, Number 4, 1 November 2001, pp. 245-271(27), Publisher: Professional Engineering Publishing.

[4] Holroyd, T., The Acoustic Emission \& Ultrasonic Monitoring, 1st edition, 2000, Coxmoor Publishing Company, Oxford, OX7 6UP, UK.

[5] Yoshioka, T. Detection of rolling contact subsurface fatigue cracks using acoustic emission technique, Journal of the Society of Tribologists and Lubrication Engineers, Volume 49, June 1992. 


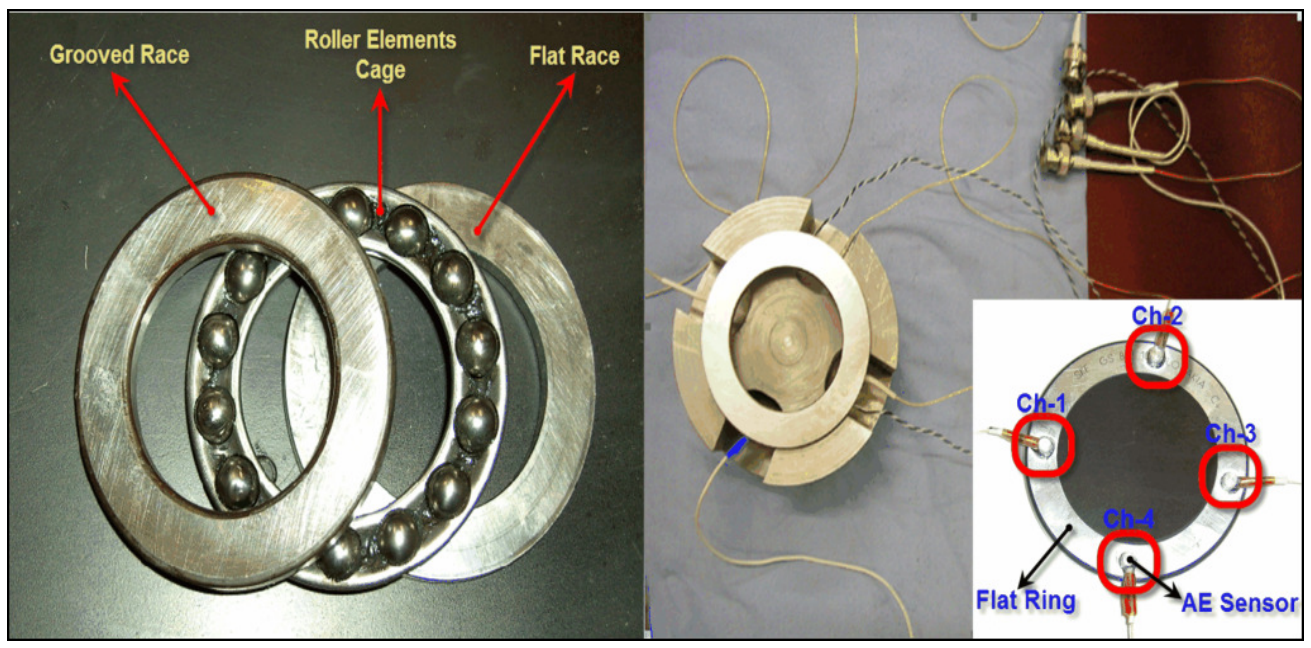

Fig. 1. Test bearing arrangement for accelerated failure on the flat race.

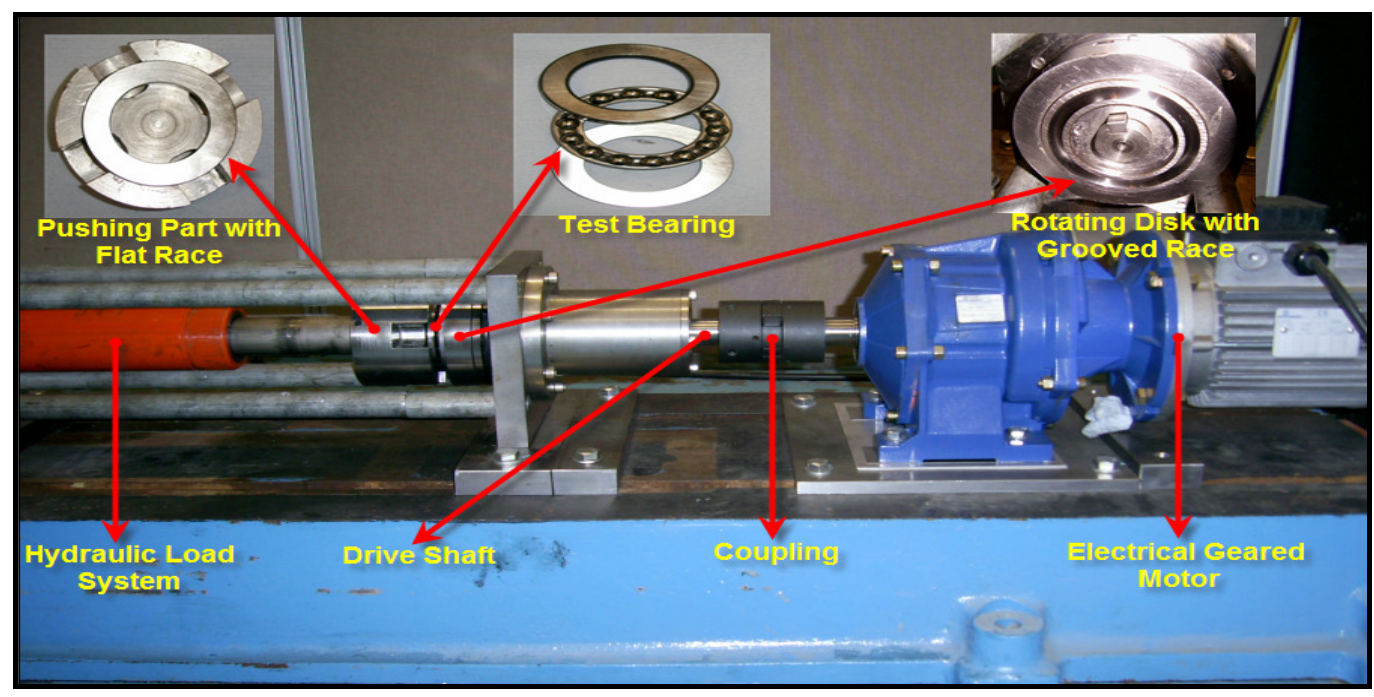

Fig. 2. Test-rig layout.

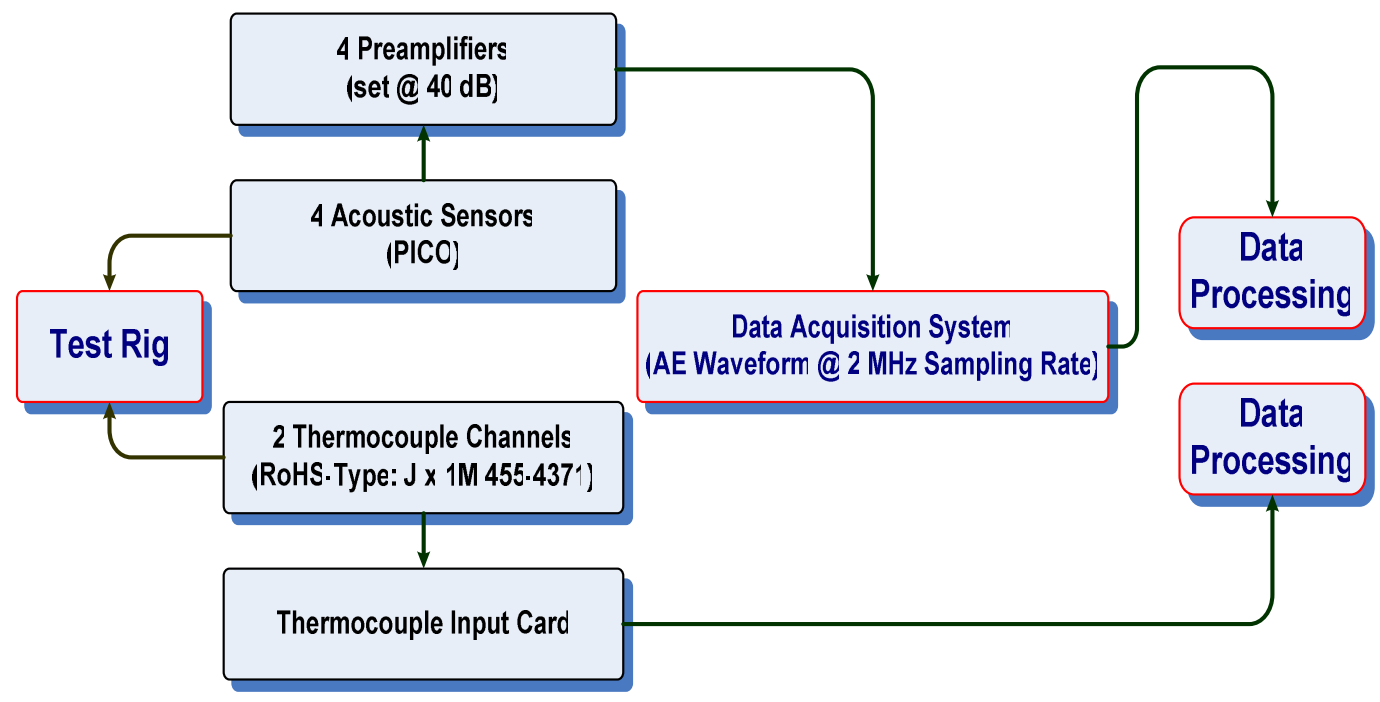

Fig. 3. Schematic of the data acquisition systems. 


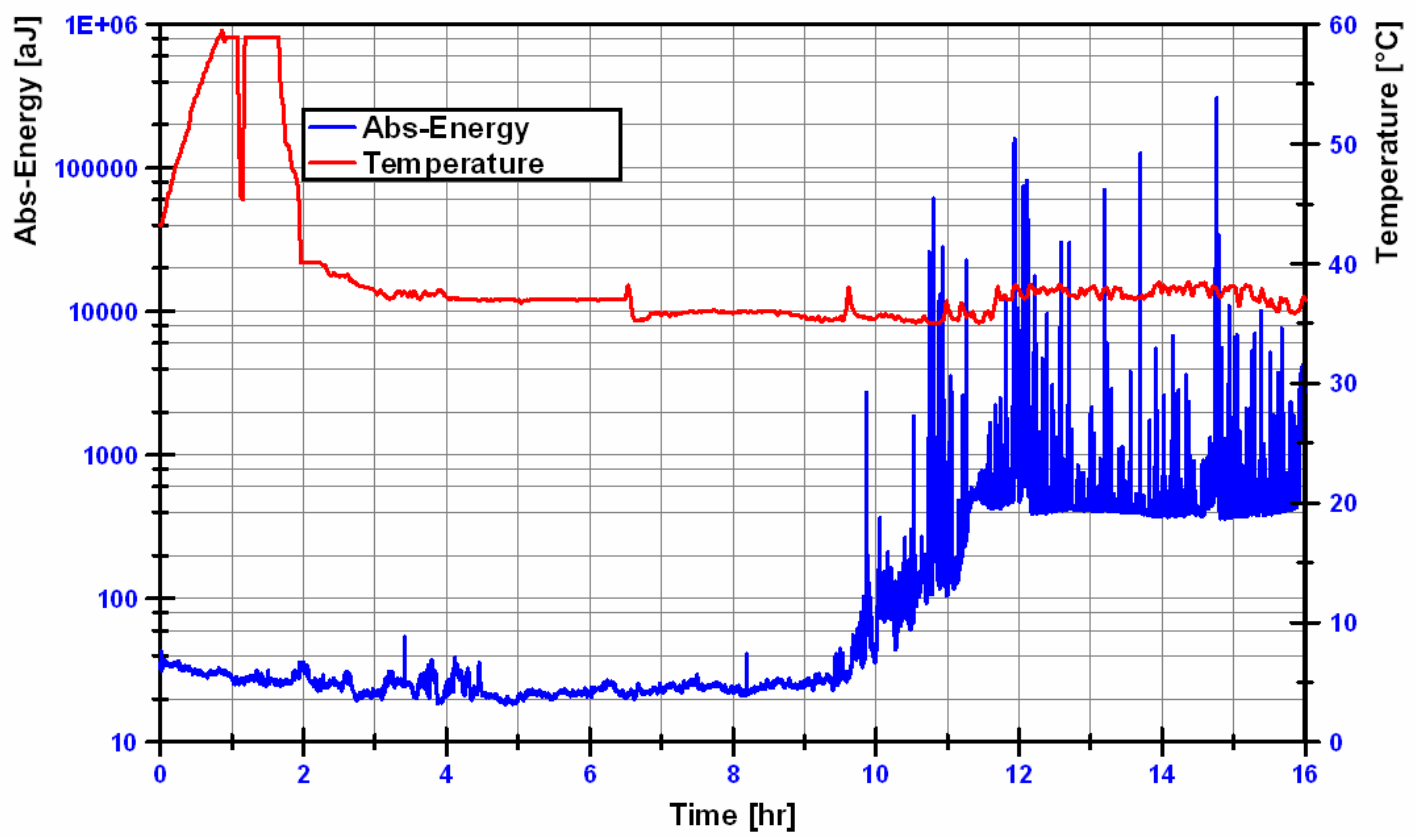

Fig. 4. Test conditions run until visually observable surface damage.

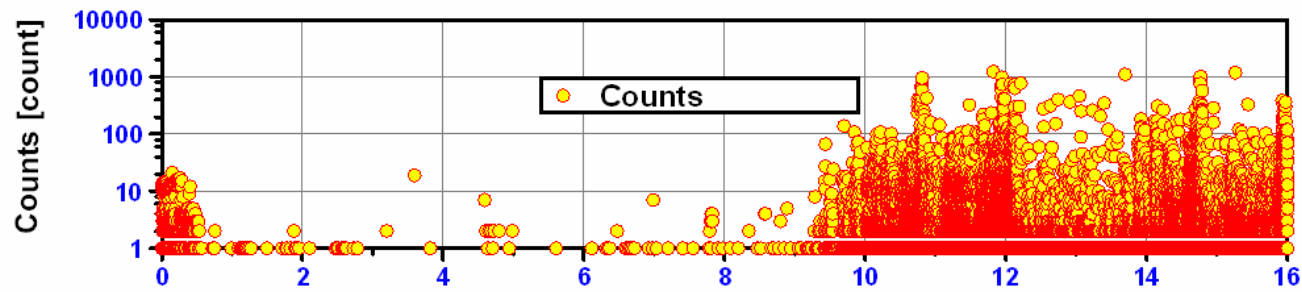

Time [hr]

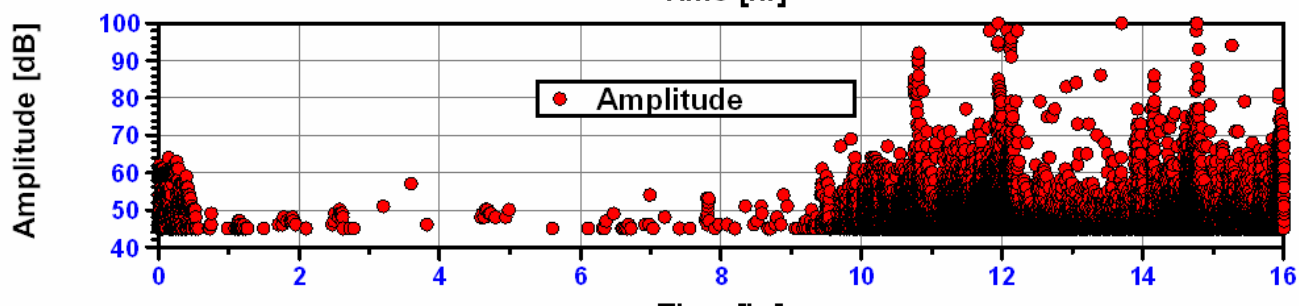

Time [hr]

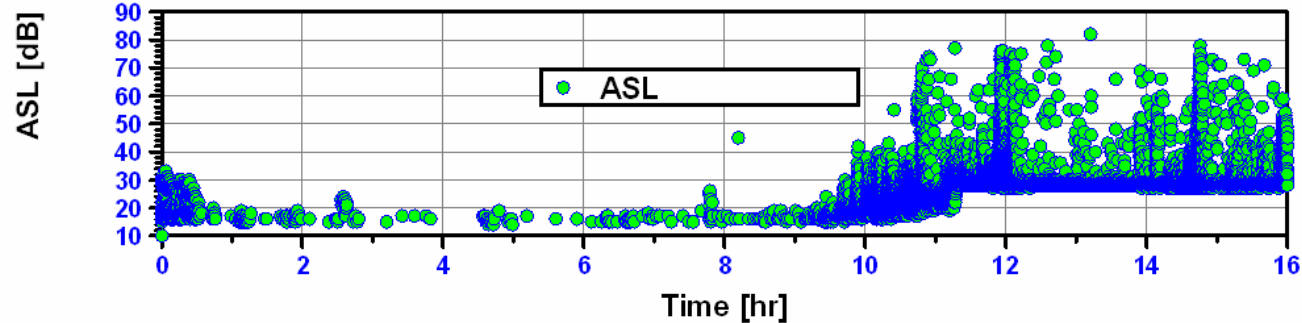

Fig. 5. Classical AE parameters. 

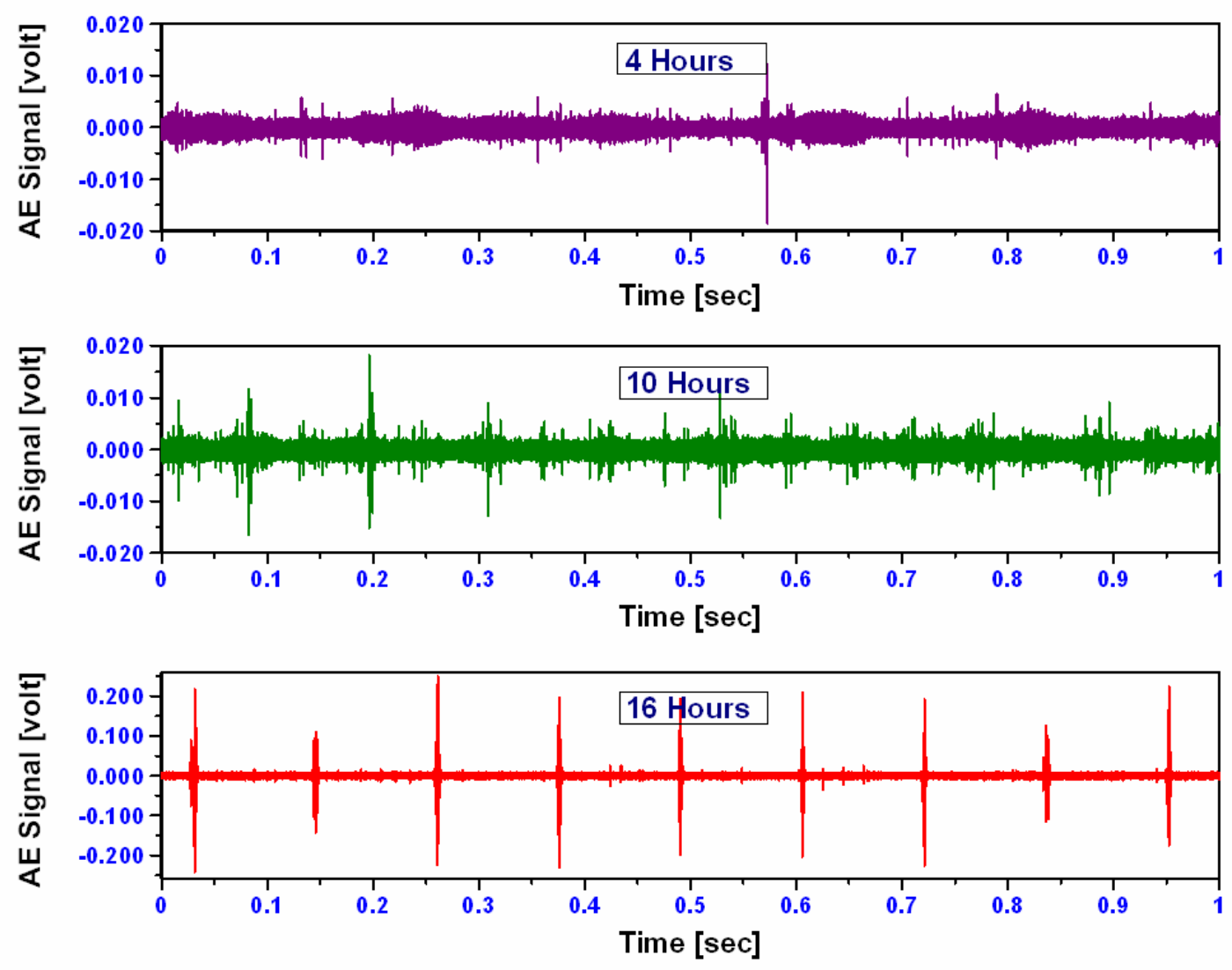

Fig. 6. AE waveform.

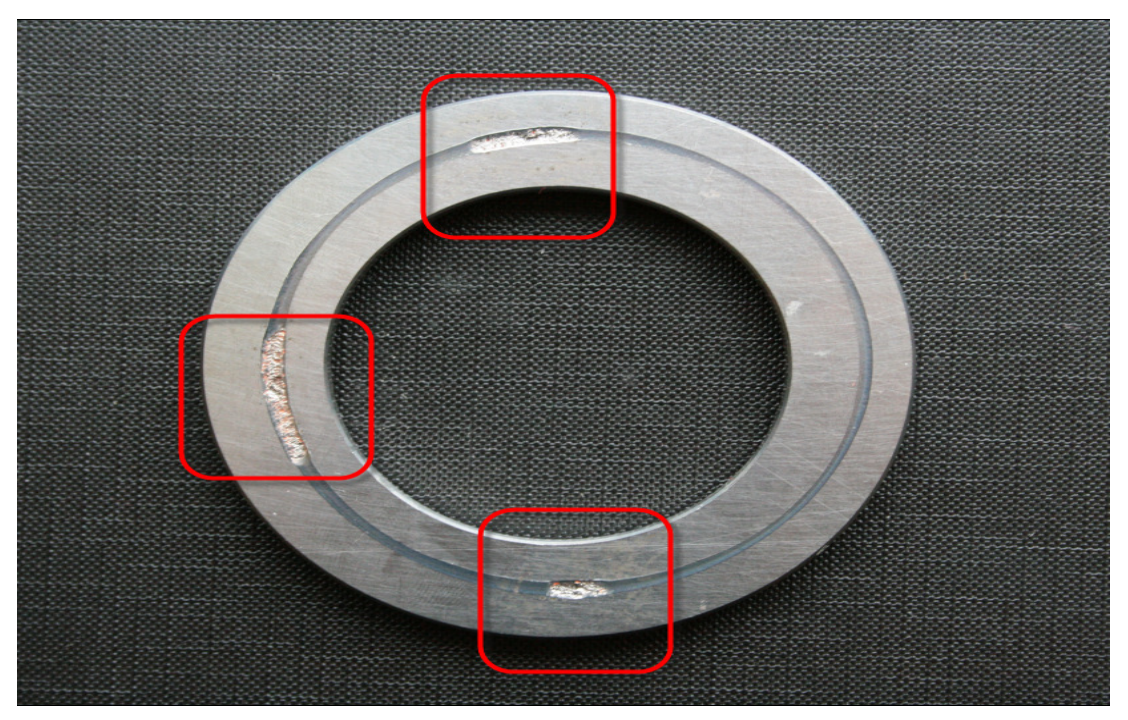

Fig. 7. Crack zones on flat ring. 


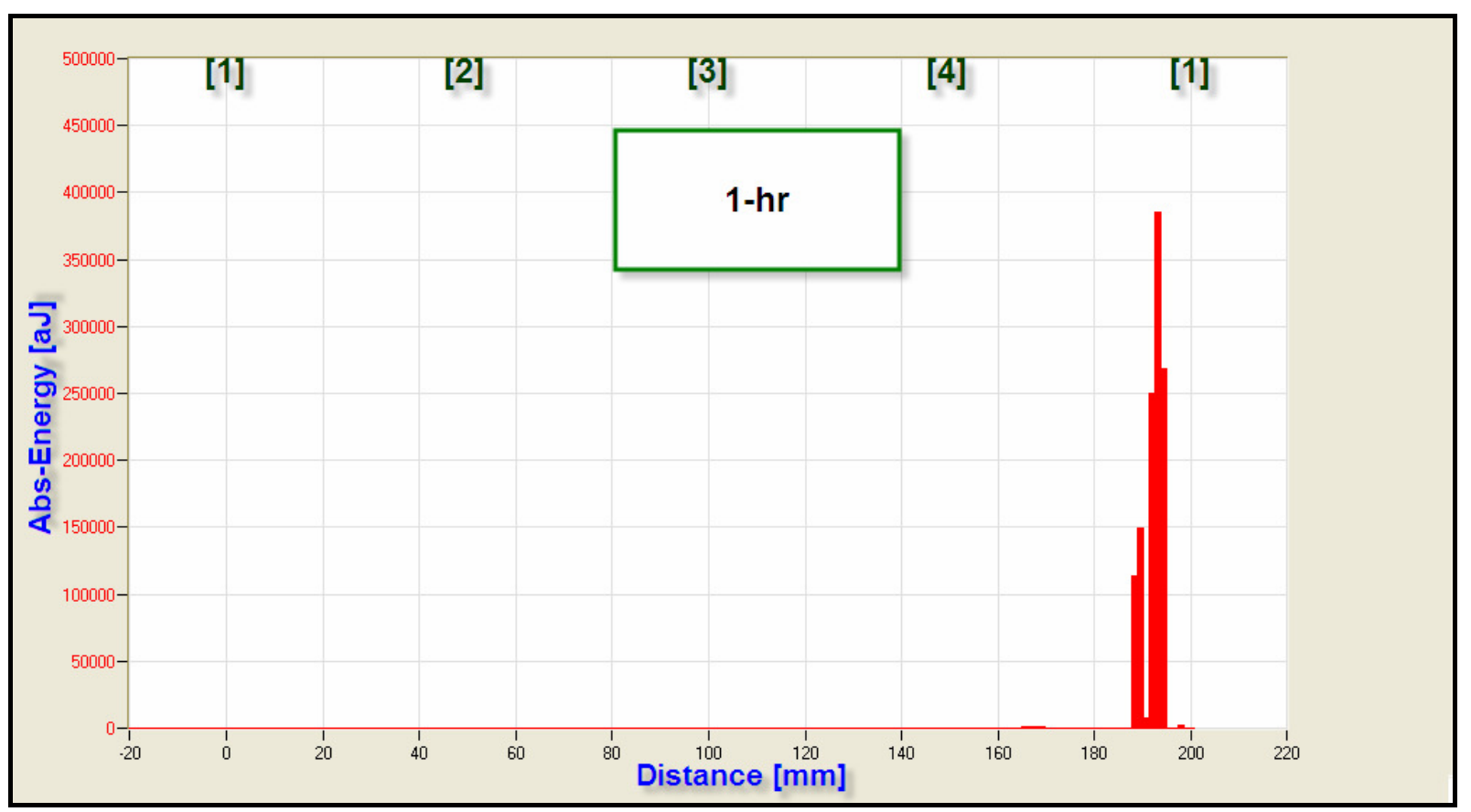

Fig. 8. Source location estimates of AE events at 1-hr operation.

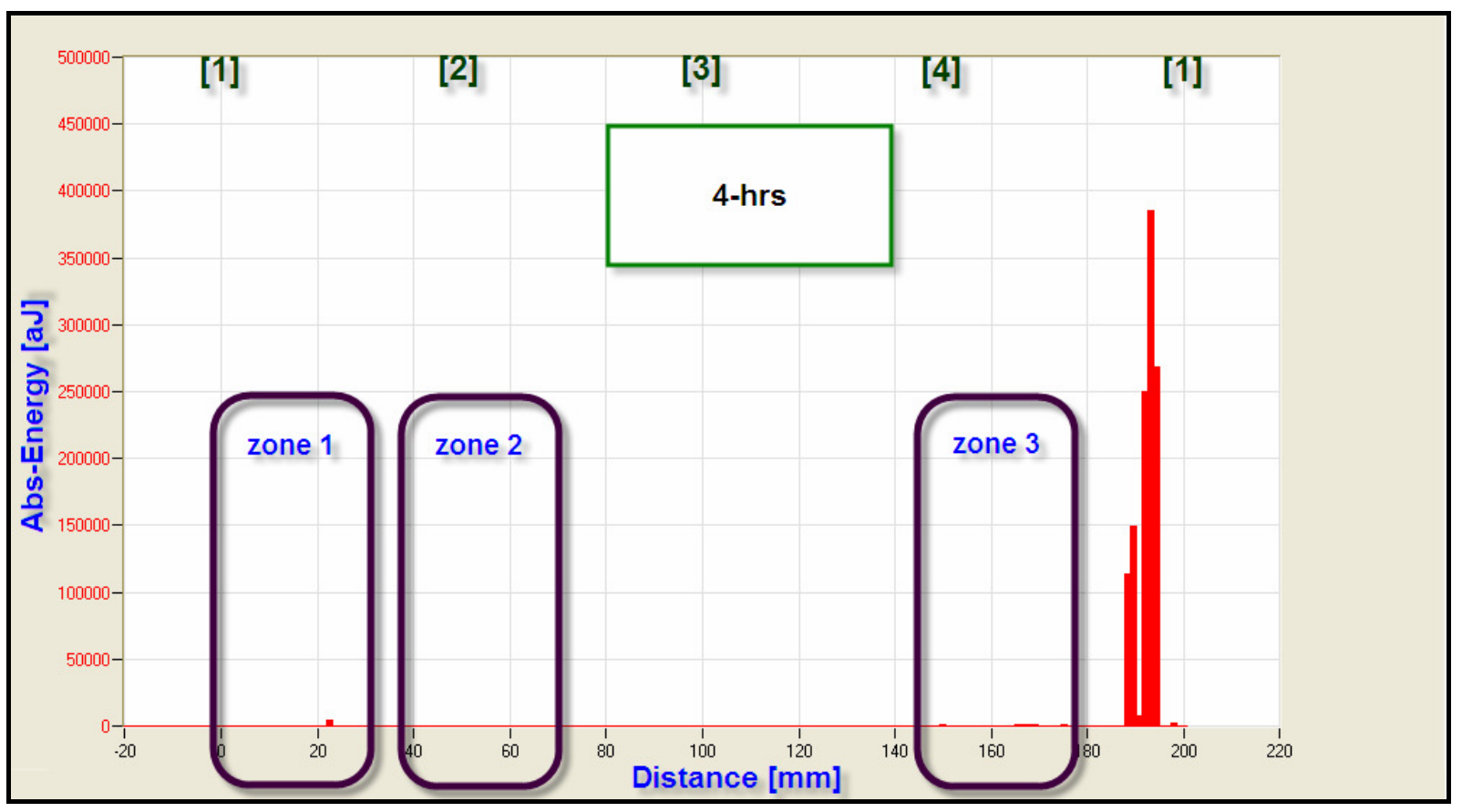

Fig. 9. Source location estimates of AE events at 4-hrs operation. 


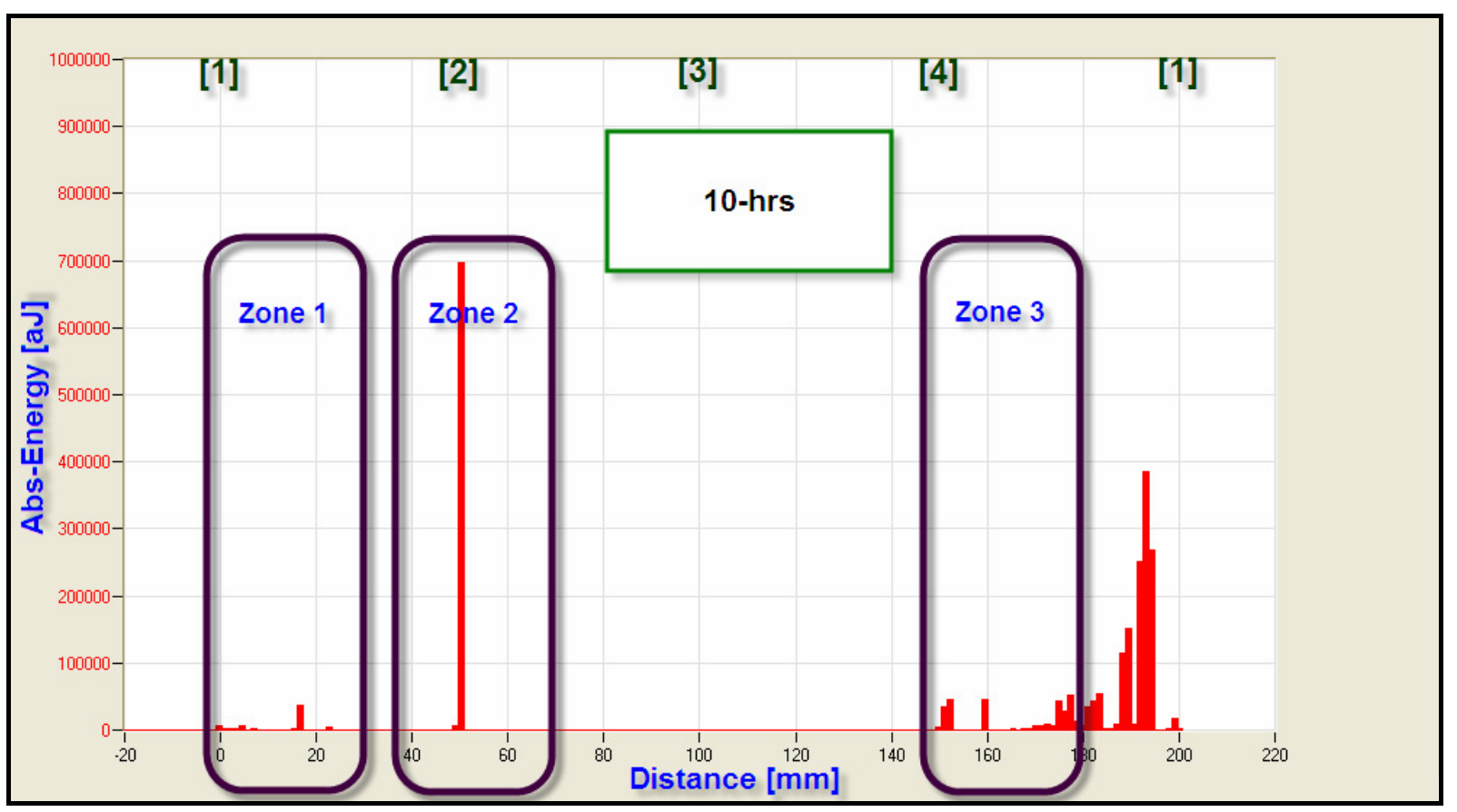

Fig. 10. Source location estimates of AE events at 10-hrs operation.

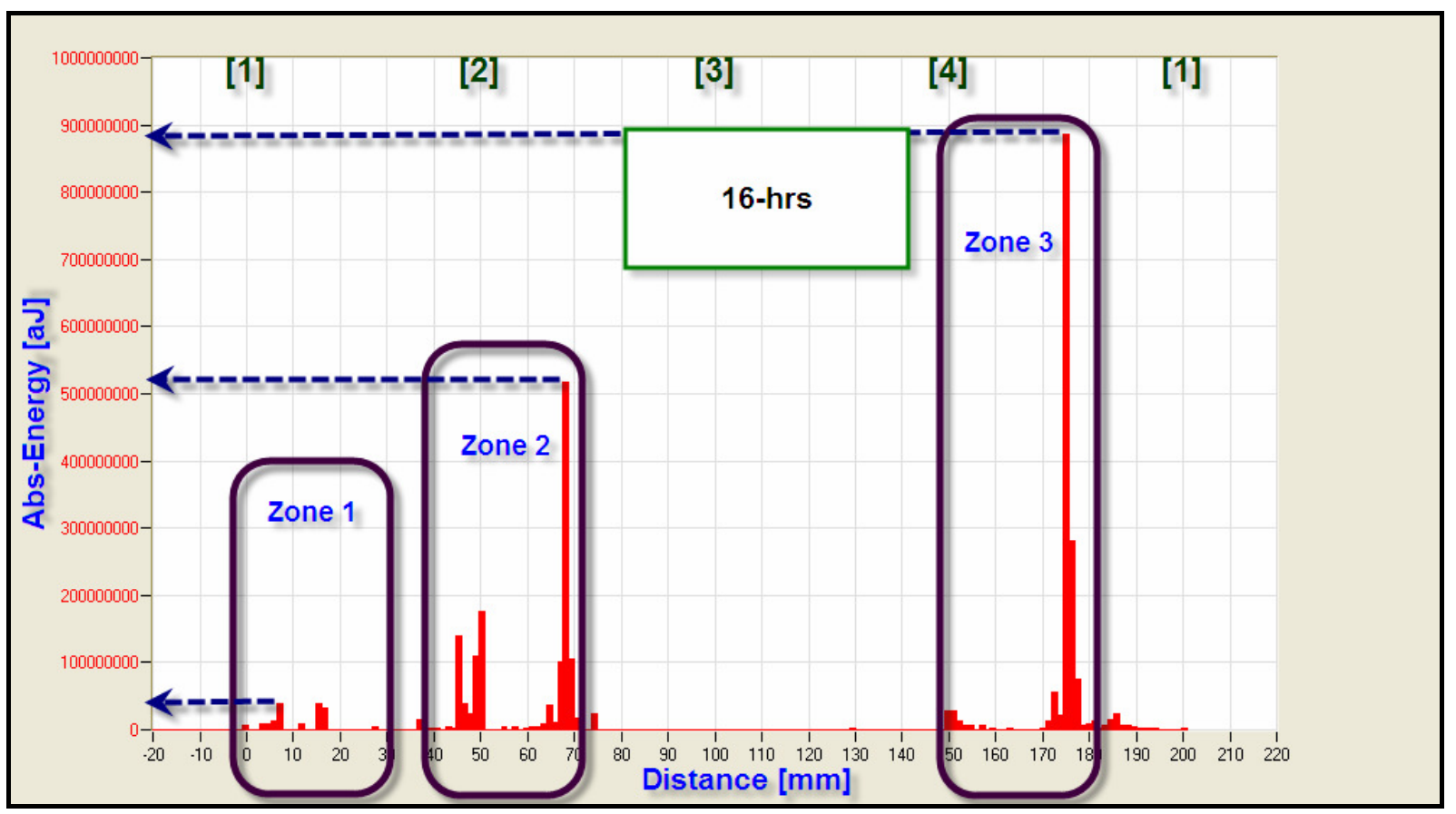

Fig. 11. Source location estimates of AE events at 16-hrs operation. 